\title{
Biodegradação de polipropileno recilado (ppr) e de poli (tereftalato de etileno) reciclado (petr) por Pleurotus ostreatus
}

\author{
Paulo César de Faria ${ }^{1}$, Elisabeth Wisbeck ${ }^{2}$, \\ Luciana Pereira Dias ${ }^{3}$
}

\author{
1,2 Programa de Pós-Graduação em Engenharia de Processos - Univille - CP: 89201-974 Joinville, SC. \\ e-mail: lacfaria@gmail.com; elisabeth.wisbeck@univille.ne \\ ${ }^{3}$ Programa de Pós-Graduação em Biotecnologia Industrial, Escola de Engenharia de Lorena da Universidade de São Paulo - \\ EEL/USP - CP: 12602-810 Lorena,SP. \\ e-mail: lucianapereiradias@live.com
}

\section{RESUMO}

Plásticos como o polipropileno (PP) e o poli (tereftalato de etileno) (PET) são produzidos a partir do petróleo que não são fontes renováveis e levam muitos anos para desaparecerem do ambiente onde são depositados, após sua utilização.

Fungos do gênero Pleurotus, por possuírem um complexo enzimático único, que os habilita a degradar materiais lignocelulósicos, vêm sendo vastamente estudados. Estes fungos além de possuírem propriedades nutricionais têm aplicações em biorremediações tais como a biodegradação de 2,4-diclorofenol, poli (tereftalato de etileno) e poliuretanos.

Neste trabalho, estudou-se a biodegradação dos polímeros PP e PET reciclados (PPr, PETr), por Pleurotus ostreatus DSM 1833 em meio de cultivo sólido, usando o meio de cultivo POL, sem glicose. Os polímeros PPr e PETr, na forma de pellets e de flakes, respectivamente, foram depositados em placas de Petri contendo o meio de cultivo. As placas previamente pasteurizadas foram inoculadas com micélio do $P$. ostreatus e incubadas a $30^{\circ} \mathrm{C}$. A caracterização dos polímeros foi feita pelos testes de perda de massa (\%) e pelas curvas de calorimetria diferencial exploratória (DSC).

Após 45 dias de biodegradação o PETr apresenta 3,3\% de perda de massa enquanto o PPr 0,3\%. Quanto às curvas obtidas pelo DSC do grau de cristalinidade $\left(\alpha_{c}\right)$ os polímeros apresentaram os seguintes valores: para o PETr biodegradado em 45 dias foi de 13\%, enquanto que o controle abiótico foi de $29 \%$. Já o $\alpha_{c}$ do PPr foi de 31\% no controle abiótico de 45 dias e aumentou para 35\% no teste de biodegradação.

Palavras-chave: biodegradação, polipropileno, poli (tereftalato de etileno), Pleurotus ostreatus.

\section{ABSTRACT}

Plastics such as polypropylene (PP) and poly (ethylene terephthalate) (PET) are produced from oil are nonrenewable sources and take many years to disappear from the environment where they are deposited after use.

Fungi of the genus Pleurotus, by having a single enzyme complex, which enables them to degrade lignocellulosic materials have been widely studied. These fungi in addition to possessing nutritional properties have applications in bioremediations such as 2, 4-dichlorophenol biodegradation of poly (ethylene terephthalate), and polyurethanes.

In this work, we studied the biodegradation of polymers PP and recycled PET (PrP, PETr) by Pleurotus ostreatus DSM 1833 in a solid farming, using the POL culture medium without glucose. The PPR and PETr polymers in the form of flakes and pellets, respectively, were deposited on Petri plates containing the culture medium. Previously pasteurized plates were inoculated with mycelium of $P$. ostreatus and incubated at $30{ }^{\circ} \mathrm{C}$.

The characterization of the polymers was made by the test mass loss (\%) and the curves of differential scanning calorimetry (DSC). 
After 45 days of biodegradation PETr presents the 3.3\% mass loss while the PrP was 0.3\%. With regard to the curves obtained from DSC crystallinity $\left(\alpha_{c}\right)$ polymers had the following values: for PETr biodegraded in 45 days was $13 \%$, while the abiotic control was $29 \%$. Since the $\operatorname{PrP} C \alpha_{c}$ was $31 \%$ in the control abiotic 45 days and increased to $35 \%$ in the biodegradation test.

Keywords: biodegradation, polypropylene, poly (ethylene terephthalate), Pleurotus ostreatus.

\section{INTRODUÇÃO}

O surgimento dos plásticos relaciona a necessidade de novos materiais usados no cotidiano com maior durabilidade e multifuncionalidade em função de suas propriedades, versatilidade e preço. Atualmente, os plásticos fazem parte do nosso cotidiano mais do que imaginamos, estão presentes nas fibras têxteis sintéticas, nas embalagens em geral, na construção civil, nos utensílios domésticos, nos aparelhos eletrônicos, nos carros, na medicina, entre muitos outros segmentos. Nos últimos anos, seu uso indiscriminado vem preocupando algumas partes da sociedade, por um lado são de grande importância e aplicabilidade, mas por outro, representam grandes problemas ambientais e consequentemente, o polipropileno (PP) e o poli (tereftalato de etileno) (PET), tornam-se um material nocivo ao sistema ecológico [1,ㅡ].

Desde 1940, os materiais plásticos mais usados são polietileno (PE), polipropileno (PP), poli (cloreto de vinila) (PVC) e poli (tereftalato de etileno) (PET) e o que preocupa é que a maioria dos plásticos obtidos do petróleo leva em média mais de 200 anos para a sua completa degradação na natureza [3]].

O polipropileno (PP) possui baixa densidade, é semicristalino, com uma vasta aplicação em embalagens alimentares, potes de margarina, seringas descartáveis, equipamentos médico-cirúrgico, fibras e fios têxteis, entre outros [4]. O poli (tereftalato de etileno) - PET como é conhecido, se cristaliza com facilidade e apresenta considerável resistência mecânica, térmica e química. Sendo de grande utilidade, em copos, garrafas para refrigerantes, filmes, entre outros [므, $\underline{6}, \underline{7}]$.

A degradação de um polímero é um processo irreversível ocasionado por vários fatores. Responsável pela perda de suas propriedades, tais como a cisão da cadeia polimérica e sua alteração estrutural [్]

A biodegradação consiste no tratamento que emprega microrganismos que degradam e transformam compostos orgânicos existentes nos solos contaminados, aquíferos, lodos e resíduos, em compostos menos complexos e mais facilmente degradáveis, podendo-se chegar até a sua mineralização. Esses processos vêm sendo muito utilizados na área de tecnologia ambiental [ㅁ-미]

Fungos do gênero Pleurotus, por possuírem um complexo enzimático único, que os habilita a degradar materiais lignocelulósicos, vêm sendo estudados. Têm sido aplicados na biodegradação de 2,4-diclorofenol [11], de poli (tereftalato de etileno) (PET) [12] e de poliuretanos (PU) [13].

Assim sendo, este trabalho teve por objetivo verificar a capacidade da espécie Pleurotus ostreatus DSM 1833 em degradar os polímeros PP e PET reciclados (PPr e PETr) em meio de cultivo sólido. Nesse contexto, foi avaliada a perda de massa e o grau de cristalinidade dos polímeros.

\section{MATERIAL E MÉTODOS}

\subsection{Microrganismo e meio de cultivo}

Foi utilizado o isolado Pleurotus ostreatus (DSM 1833), proveniente da Deutsche Sammlung von Mikroorganismen und Zellkulturen Gmbh (DSMZ), Alemanha. O meio de cultura foi esterilizado a $121^{\circ} \mathrm{C}$ e as culturas foram crescidas em placa de Petri contendo o meio TDA (extrato de trigo, dextrose e ágar) sob refrigeração $\left(4^{\circ} \mathrm{C}\right)$ e os repiques foram realizados a cada três meses. Para os ensaios de biodegradação, o utilizado meio de cultura POL modificado contendo $\left(\left(\mathrm{NH}_{4}\right)_{2} \mathrm{SO}_{4} 5 \mathrm{~g} / \mathrm{L} ; \mathrm{MgSO}_{4} .7 \mathrm{H}_{2} \mathrm{O} 0,2 \mathrm{~g} / \mathrm{L} ; \mathrm{K}_{2} \mathrm{HPO}_{4}\right.$ 1,0g/L, extrato de levedura 2,0g/L, peptona 1,0g/L e 15g/L ágar) [14]. A glicose não foi adicionada para que a principal fonte de carbono fosse o polímero.

\subsection{Polímeros utilizados}

Os polímeros utilizados foram o polipropileno reciclado (PPr), fornecido pela recicladora Reciplasc (SC) e o poli(tereftalato de etileno) reciclado (PETr), fornecido pela Braskem (BA) na forma de pellets e flakes, respectivamente, (Figura 1). 


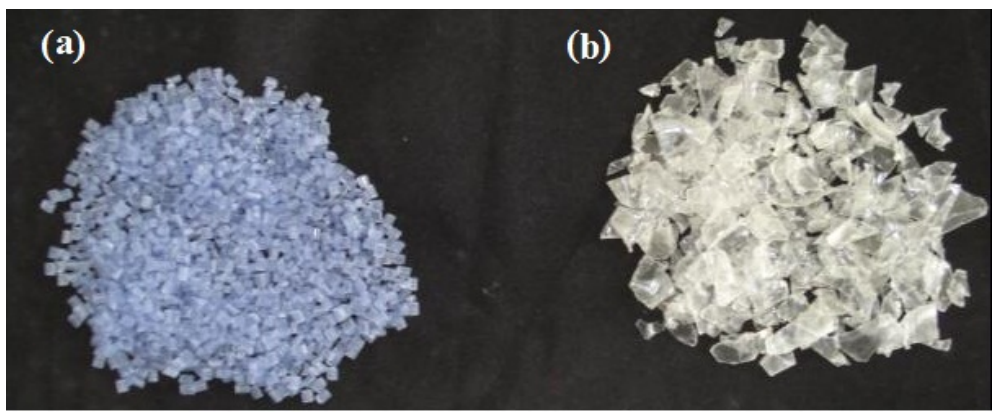

Figura 1: Polímeros utilizados: (a) PPr na forma de pellets; (b) PETr na forma de flakes.

\subsection{Ensaios de Biodegradação}

No ensaio de biodegradação, aproximadamente 0,1g do polímero PPr ou PETr, foi previamente pasteurizados em vapor d'agua por 1 hora, em seguida, foi adicionado nos quatro quadrantes da placa de Petri contendo meio POL modificado. No centro inoculou-se um disco de ágar (12 mm de diâmetro) contendo micélio de $P$. ostreatus DSM 1833. As placas, então, foram incubadas a $30^{\circ} \mathrm{C}$ por 30 e 45 dias, respectivamente.

Os polímeros foram separados do micélio, com o auxílio de uma espátula e tratados conforme descrito no item 2.4. O crescimento micelial foi avaliado de forma visual. Também foram realizados, ensaios para avaliar a influência do meio POL modificado sobre os polímeros (Controle abiótico) e sobre o crescimento de $P$. ostreatus DSM 1833 (Controle biótico). Todos os ensaios foram realizados em duplicatas.

Como controle abiótico, placas contendo meio POL e polímeros PPr ou PETr, devidamente pasteurizados, foram mantidos a $30^{\circ} \mathrm{C}$ por 30 e 45 dias. Após este tempo, os polímeros foram tratados como descrito no item 2.4. Como controle biótico, placas de Petri contendo meio POL foram inoculadas com um disco de ágar (12 mm de diâmetro) contendo micélio de $P$. ostreatus, incubadas a $30^{\circ} \mathrm{C}$ por 30 e 45 dias. $\mathrm{O}$ crescimento micelial foi avaliado de forma visual e comparado com o crescimento micelial que foi obtido nos experimentos de biodegradação.

\subsection{Caracterização dos polímeros}

Para a determinação da massa dos polímeros utilizou-se a metodologia ASTM D 5247-92 [15], que consiste em colocar as amostras de PPr e PETr, em solução de $\mathrm{NaOH} 5 \mathrm{M}$, por aproximadamente 8 horas, a temperatura ambiente e em seguida 8 horas em repouso com água destilada. Após, foram colocados em estufa a $50^{\circ} \mathrm{C}$ por 12 horas e pesados em balança analítica [12]. Em seguida as massas das amostras foram medidas em balança analítica Mettler AT-250 com precisão de $10^{-4} \mathrm{~g}$, em duplicata. A perda de massa (Pm\%) dos polímeros foi expressa em relação à massa inicial (equação 1).

$$
\text { Pm (\%) = Massa inicial - Massa final / Massa inicial*100 }
$$

O grau de cristalinidade $\left(\alpha_{c}\right)$ dos polímeros foi medido de acordo com a equação 2. As temperaturas de transição vítrea, fusão e cristalização, foram medidas através do método de calorimetria exploratória diferencial (DSC) onde $20 \mathrm{mg}$ das amostras foram adicionadas em cadinhos de alumínio e aquecidas de 25 a $350{ }^{\circ} \mathrm{C}$ a $10{ }^{\circ} \mathrm{C} / \mathrm{min}$.

$$
\alpha \mathrm{C}=\Delta \mathrm{H} \mathrm{m} / \Delta \mathrm{H} \mathrm{m}^{0} * 100
$$

Onde $\Delta \mathrm{H}_{\mathrm{m}}$ é a entalpia de fusão e $\Delta \mathrm{H}_{\mathrm{m}}{ }^{\circ}$ é a entalpia de fusão supondo uma amostra $100 \%$ cristalina

\section{RESULTADOS E DISCUSSÃO}

Podemos observar na tabela 1 os valores médios de perda de massa (\%) do polipropileno reciclado (PPr) e do poli (tereftalato de etileno) reciclado (PETr) após 30 e 45 dias de biodegradação por P. ostreatus DSM 1833 e dos controles abióticos submetidos às mesmas condições dos testes de biodegradação. 
Tabela 1: Resultados de perda de massa (\%) de PPr e PETr biodegradados por P. ostreatus DSM 1833

\begin{tabular}{ccc}
\hline & $\begin{array}{c}\text { Tempo } \\
\text { (dias) }\end{array}$ & $\begin{array}{c}\text { Perda de massa } \\
(\%)\end{array}$ \\
\hline PPr & & \\
\hline Controle abiótico & 0 & 0 \\
& 30 & 0 \\
Biodegradação & 45 & 0 \\
& 0 & 0 \\
PETr & 30 & 0,3 \\
& 45 & 0,3 \\
\hline Controle abiótico & 0 & \\
& 30 & 0 \\
Biodegradação & 45 & 0 \\
& 0 & 0 \\
& 30 & 2,4 \\
& 45 & 3,3 \\
\hline
\end{tabular}

Os resultados do controle abiótico do PPr e do PETr, apresentados na tabela 1, mostram que estes polímeros não tiveram influência do meio e das condições de cultivo, uma vez que sofreram o mesmo tratamento utilizado nos testes de biodegradação e não apresentaram perda de massa.

Os resultados da tabela 1 mostram que, apesar do pouco tempo de biodegradação, 45 dias, o PETr apresentou 3,3\% de perda de massa. Podemos salientar, que esta perda é devida ao processo de biodegradação do fungo uma vez que o controle abiótico não apresentou perda de massa. Conforme REYES [12], utilizando PET virgem na forma de pellets constatou uma perda de massa de 0,2\% em 30 dias e 1,75\% em 60 dias de cultivo submerso com $P$. sajor caju. Neste caso a variação da espécie fúngica e a diferença de estrutura física dos polímeros devem ser levadas em consideração. No entanto, MONTEIRO [16], relatou que após 85 dias de biodegradação do PETr por P. ostreatus em cultivo submerso, o PETr teve uma perda de massa de $0,8 \%$, inferior à encontrada neste trabalho. Conforme estudos realizados por SILVA [17], os Pellets de PET sofreram maior perda de massa (\%) nos intervalos de 30 dias (4,23\%), 60 dias (4,34 \%) e 90 dias (4,51\%) em cultivo submerso.

As perdas de massa do PPr após 30 e 45 dias de biodegradação foram de 0,3\% (tabela 1). MONTEIRO [16], ao utilizar PPr em experimentos de 30 e 60 dias obteve perdas de 0,15 e 0,12\%, respectivamente, resultados muito similares aos encontrados neste trabalho. Isto sugere que a espécie $P$. ostreatus não consegue, apesar do seu sistema enzimático lignocelulolítico, utilizar com facilidade este polímero como fonte de carbono.

A figura 2 apresenta o controle biótico (A) em comparação aos testes de biodegradação de PPr (B) e $\operatorname{PETr}(\mathrm{C})$ após 45 dias de cultivo.

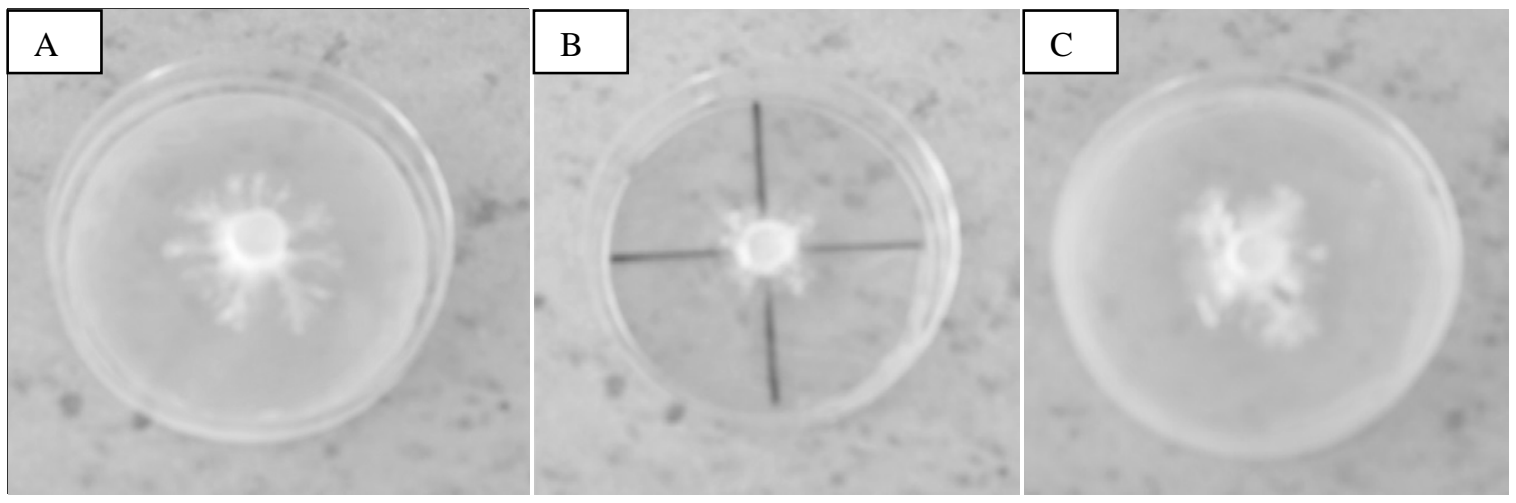

Figura 2: Micélio de P. ostreatus (DSM 1833) (A) em meio POL modificado (sem glicose), por 45 dias; (B) em meio POL modificado com PPr por 45 dias; (C) em meio POL modificado com PETr por 45 dias (C) 
Verifica-se pela figura 2 (A) que o meio de cultivo POL modificado, ou seja, sem glicose, não afetou o crescimento micelial. Assim sendo, neste trabalho, observou-se que em 45 dias o micélio ainda não havia tomado conta de toda a superfície do meio de cultivo, no entanto, o seu crescimento não foi inibido.

Ao realizar a comparação do controle abiótico (figura 2 A) com o teste de biodegradação do polipropileno reciclado (PPr) após 45 dias de cultivo (figura $2 \mathrm{~B}$ ), nota-se um crescimento micelial muito discreto, talvez pelo fato de que o ambiente não apresentasse fonte de carbono adequada para seu desenvolvimento. Entretanto, se observarmos o teste de biodegradação do poli (tereftalato de etileno) reciclado - (PETr) após 45 dias de cultivo (figura 2 C), este mostra um crescimento micelial mais acentuado que parece estar relacionado com a maior facilidade do fungo em utilizar o polímero reciclado (PETr) como fonte de carbono. Este comportamento corrobora com os resultados obtidos na tabela 1, onde a perda de massa do PPr após 45 dias de cultivo foi muito menor e menos expressiva $(0,3 \%)$ em comparação à perda de massa do PETr neste mesmo tempo (3,3\%). Porém, sabe-se que a confirmação da degradação de um polímero não envolve somente a perda de massa do polímero, mas sim alterações na sua molécula $[17, \underline{18,19]}$.

A temperatura de fusão $\left(\mathrm{T}_{\mathrm{m}}\right)$, a entalpia de fusão $\left(\Delta \mathrm{H}_{\mathrm{m}}\right)$ e o grau de cristalinidade $\left(\alpha_{\mathrm{c}}\right)$ são características dos polímeros que geralmente são afetadas pela biodegradação e são facilmente detectadas pelo método de calorimetria diferencial exploratória (DSC). As curvas de DSC para as amostras de PETr estão apresentadas nas figuras 3 e 4 e para as amostras de PPr nas figuras 5 e 6 . A Tabela 2 mostra os dados de $\mathrm{T}_{\mathrm{m}}, \Delta \mathrm{H}_{\mathrm{m}}$ e $\alpha_{\mathrm{c}}$ obtidos a partir das curvas de DSC. Os graus de cristalinidade obtidos para os polímeros foram calculados segundo a equação 2 tendo sido consideradas as entalpias de fusão para o polímero 100\% cristalino $\left(\Delta \mathrm{H}_{\mathrm{m}}{ }^{\circ}\right)$ de $140 \mathrm{~J} / \mathrm{g}$ para o PET e de $190 \mathrm{~J} / \mathrm{g}$ para o PP isotático [16].

A figura 3 apresenta as curvas de DSC do PETr sem tratamento (bruto) e do PETr pasteurizado (controle abiótico 0 dias) e observa-se uma diferença entre as áreas dos picos das amostras. De acordo com a tabela 2 verifica-se que o grau de cristalinidade da amostra sem tratamento é menor (14\%) que a amostra pasteurizada (28\%). Este fato indica a influência do tratamento térmico nesta característica do polímero. Segundo VERT et al. [a20] e FERNÁNDEZ et al. [21], a entalpia de fusão aumenta devido à degradação da fase amorfa antes da fase cristalina, permanecendo uma maior porcentagem da fase cristalina. Os valores do grau de cristalinidade para os controles abióticos não apresentaram grande variação, mostrando que as condições de cultivo não afetaram o polímero.

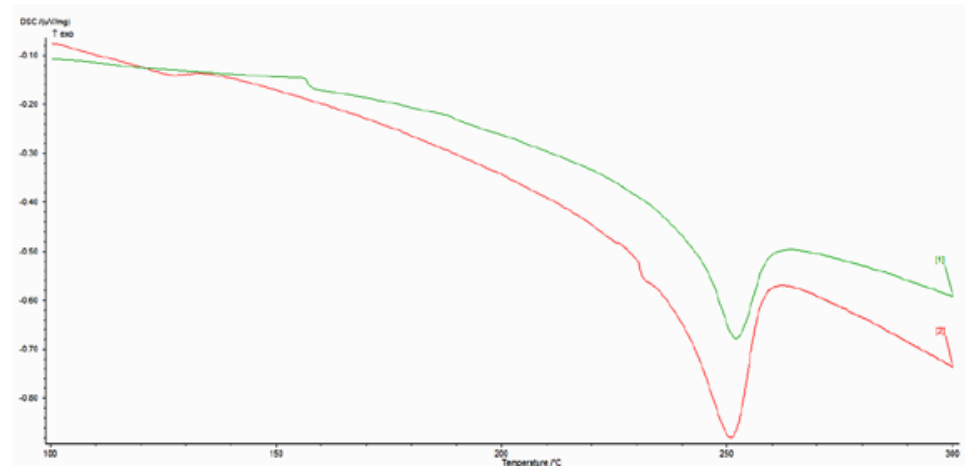

Figura 3: Curvas de DSC do PETr: bruto (1) e controle abiótico 0 dias (2)

No entanto, nos testes de biodegradação de 30 e de 45 dias verificou-se uma diminuição nos valores de $\alpha_{c}, 11$ e $13 \%$, respectivamente (tabela 2). Geralmente, um indício de degradação do polímero é o aumento da entalpia de fusão [16, 22, 23, 24] no entanto GAN et al. [25] e PENG et. al[26], ao realizarem degradação enzimática de poli ( $\varepsilon$-caprolactona) (PCL) observaram que as áreas dos picos da entalpia de fusão diminuíram gradualmente com o aumento do tempo de biodegradação, consequentemente o grau de cristalinidade também diminuiu. Os autores sugerem que a degradação tomou lugar não somente na fase amorfa, mas também na fase cristalina e eles verificaram que a estrutura cristalina do PCL foi eficientemente destruída. Se este fenômeno estiver acontecendo nas amostras de biodegradação do PETr em nossos experimentos, vem de encontro com os dados da tabela 1 que mostram uma perda de massa de 3,3\% para a biodegradação de 45 dias.

Observa-se ainda da figura 4 e na tabela 2 que as temperaturas de fusão $\left(T_{m}\right)$ não apresentaram variação para as diferentes amostras de PETr. 


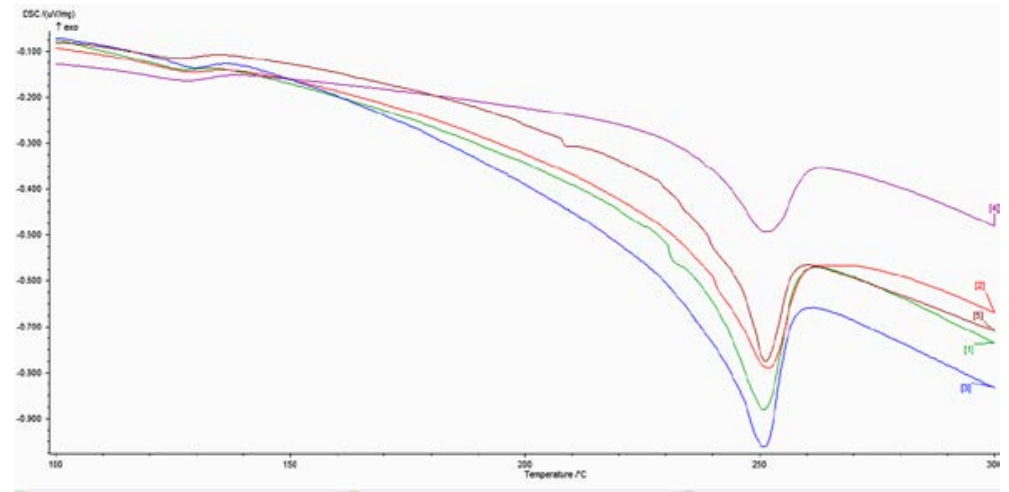

Figura 4: Curvas de DSC do PETr: Curvas de DSC do PETr: controle abiótico 0 dias (1), controle abiótico 30 dias (2), controle abiótico 45 dias (3), biodegradação 30 dias (4) e biodegradação 45 dias (5)

Tabela 2: Dados obtidos por DSC (Tm, $\Delta \mathrm{Hm}$ e $\alpha \mathrm{c})$ para as amostras de PETr e PPr nos controles abióticos e biodegradação

\begin{tabular}{ccccc}
\hline & $\begin{array}{c}\text { Tempo } \\
\text { (dias) }\end{array}$ & $\begin{array}{c}\mathrm{T}_{\mathrm{m}} \\
\left({ }^{\circ} \mathrm{C}\right)\end{array}$ & $\begin{array}{c}\Delta \mathrm{H}_{\mathrm{m}} \\
(\mathrm{J} / \mathrm{g})\end{array}$ & $\begin{array}{c}\alpha_{\mathrm{c}} \\
(\%)\end{array}$ \\
\hline PETr bruto & & 252 & 19,6 & 14 \\
Controle abiótico & 0 & 251 & 39,4 & 28 \\
& 30 & 252 & 31,4 & 22 \\
Biodegradação & 45 & 251 & 41,4 & 29 \\
& 30 & 252 & 15,3 & 11 \\
\hline PPr bruto & 45 & 251 & 18,2 & 32 \\
Controle abiótico & 0 & 174 & 60,3 & 31 \\
& 30 & 172 & 59,5 & 32 \\
Biodegradação & 45 & 174 & 61,4 & 31 \\
& 30 & 173 & 59,1 & 35 \\
\hline
\end{tabular}

A Figura 5 apresenta as curvas de DSC do PPr sem tratamento (bruto) e do PPr pasteurizado (controle abiótico 0 dias) e não verifica-se diferença entre as áreas dos picos das amostras. De acordo com a tabela 2, o grau de cristalinidade da amostra sem tratamento e da amostra pasteurizada são similares mostrando que o tratamento térmico não teve influência nesta característica do polímero.

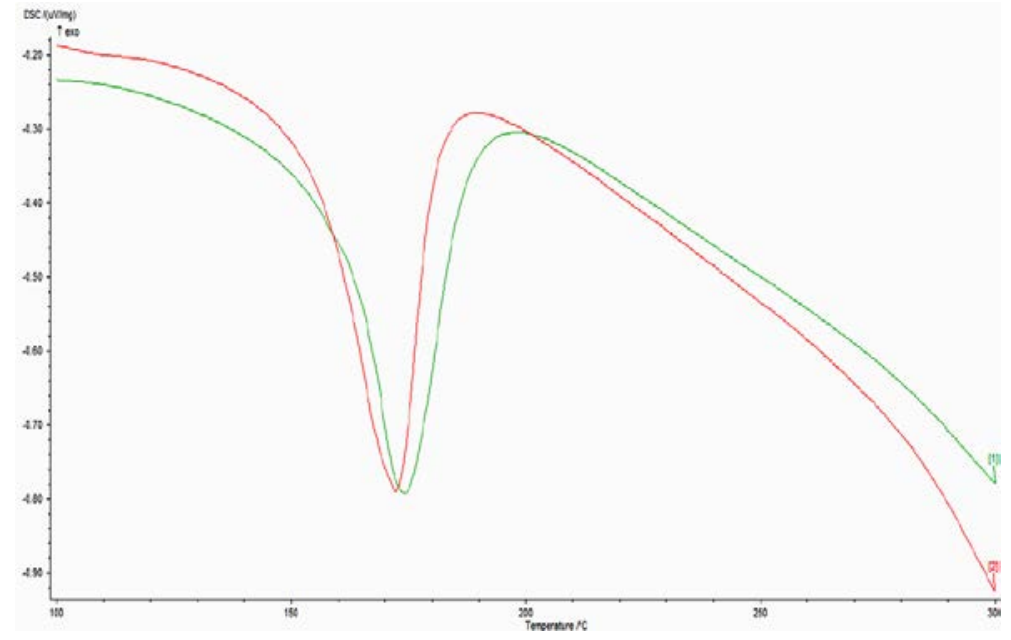

Figura 5: Curvas de DSC do PPr: bruto (1) e controle abiótico 0 dias (2) 
Nas curvas de DSC do PPr apresentadas na Figura 6 não observa-se variação no perfil das curvas, bem como na temperatura de fusão (Tabela 2). O grau de cristalinidade obtido para as amostras dos controles abióticos de PPr ficou em torno de 31-32\% enquanto que para as amostras de biodegradação em $35 \%$. Este pequeno aumento de $\alpha_{\mathrm{c}}$ pode estar relacionado à perda de massa de $0,3 \%$ da fase amorfa do PPr (Tabela 1 ) concordando com os resultados obtidos por PEZZIN [22], TSUJI [23] e MONTEIRO [16].

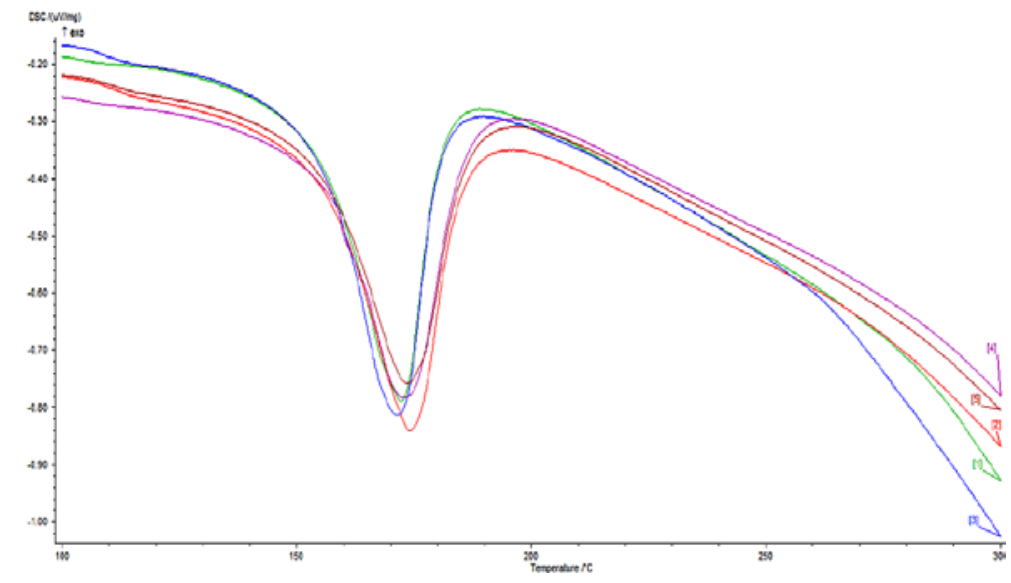

Figura 6: Curvas de DSC do PPr : controle abiótico 0 dias (1), controle abiótico 30 dias (2), controle abiótico 45 dias (3), biodegradação 30 dias (4) e biodegradação 45 dias (5).

\section{CONCLUSÃO}

De acordo com os resultados, pode-se concluir:

1) Os controles abióticos do $\operatorname{PPr}$ e do $\operatorname{PETr}(0,30$ e 45 dias) não sofreram influência do meio e das condições de cultivo uma vez que não apresentaram perda de massa (\%) e pouca variação no grau de cristalinidade $\left(\alpha_{c}\right)$.

2) Perdas de massa de 2,4 e 3,3\% foram alcançadas para os testes de biodegradação do PETr em 30 e 45 dias, respectivamente. PPr, nos mesmos tempos, sofreu uma perda de massa de $0,3 \%$.

3) As análises de DSC mostraram diferença nos graus de cristalinidade $\left(\alpha_{c}\right)$ entre o PETr bruto (14\%) e o PETr pasteurizado (28\%), indicando a influência do tratamento térmico nesta característica do polímero. Isto não foi observado para o PPr.

4) Os testes de biodegradação do PETr por 30 e 45 dias apresentaram diminuição no grau de cristalinidade, em relação aos controles abióticos, sugerindo degradação não somente da fase amorfa, mas também da fase cristalina do polímero.

5) Os testes de biodegradação do PPr por 30 e 45 dias mostraram aumento no grau de cristalinidade, em relação aos controles abióticos, sugerindo degradação da fase amorfa do polímero.

\section{BIBLIOGRAFIA}

[1] PRADO, M.R., Análise do Inventário do Ciclo de Vida de Embalagens de Vidro, Alumínio e pet utilizadas los Uma Indústria de Refrigerantes no Brasil, Tese de Doutorado, Universidade Federal do Paraná. Brasil, 2007.

[2] BACH, C., DAUCHY, X., CHAGNON, M.C., et al.," Chemical compounds and toxicological assessments of drinking water stored in polyethylene terephthalate (PET) bottles: A source of controversy reviewed”, Water Research, v. 46, n. 3, 1, pp.571-583, 2012.

[3] FRANCHETTI, S.M.M., MARCONATO, J.C., "Polímeros biodegradáveis uma solução parcial para diminuir a quantidade dos resíduos plásticos”, Química Nova, v. 29, n.4, pp. 811-816, 2006.

[4] BLASS, A. Processamento de Polímeros, 2a edição, Florianópolis-SC, Editora da UFSC, 2001.

[5] MULLER, R.J., Kleeberg, I., Deckwer, W.D.,"Biodegradation of polyesters containing aromatic constituents”, Journal of Biotechnology, v. 86, n.2, pp. 87-95, 2001.

[6] CANEVArolO, S. V. Ciência dos Polímeros.1ª ed., São Paulo, ArtLíber, 2002. 
[7] PACHECO, E.B. Material de engenharia à base de pet reciclado. Estudo do processo para implantação de uma unidade recicladora na região sul fluminense. http://www.abipet.org.br/noticias/vencedor_2000_B.doc. acessado em julho de 2012.

[8] ROSA, D.S., PANTANO FILHO, R. Biodegradação: Um ensaio com polímeros, Itatiba, editora Moara, 2003.

[9] BENTO, F.M., CAMARGO, F. A. O., OKEKE, B.,“Bioremediation of soil contaminated by diesel oil”, Brazilian Journal of Microbiology, v.34, Sup.1, pp. 65-68, 2003.

[10] GAYLARDE, C.C., BELLINASO, M. L., MANFIO, G.P., "Aspectos biológicos e técnicos da biorremediação de xenobióticos”, Biotecnologia Ciência \& Desenvolvimento, n. 34, pp. 36-43, 2005.

[11] SILVA, H.H.B., Biodegradação de 2,4-diclorofenol por Pleurotus ostreatus DSM 1833, Dissertação de Mestrado., Programa de Mestrado em Saúde e Meio Ambiente, Universidade da Região de Joinville, Brasil, 2005

[12] REYES, L.J., Estudo dedegradação de polietileno tereftalato (PET) por fungos basidiomicetos ligninolítico, Dissertação de Mestrado, Universidade Estadual de Campinas. Brasil, 2003.

[13] KLOSS, R.J., Síntese e caracterização de poliuretanos biodegradáveis à base de Poli ( $\varepsilon$ caprolactona) diol, Tese de Doutorado, Universidade do Paraná. Brasil, 2007.

[14] MAZIERO, R., CAVAZZONI, V., BONONI, V.L.R., "Screening of Basidiomycetes for the Production of Exopolysaccharide and Biomass in Submerged Culture”, Revista de Microbiologia, v. 30, n.1, pp. 77-84, 1999

[15] ASTM D 5247-92 - Standard Test Method for Determining the Aerobic Biodegradability of Degradable Plastics by Specific Microorganism. GB 18006. 1, 1999.

[16] MONTEIRO, A.M.C. Biodegradação de polipropileno(PP) e poli(tereftalato de etileno)(PET) reciclados utilizando Pleurotus ostreatus DSM 1833 em cultivo submerso, Trabalho de Conclusão de Curso, Departamento de Química Industrial, Universidade da Regiãode Joinville, 57p, 2007.

[17] SCOTT, G., GILEAD, D. “Degradable Polymers”, London.Chapman \& Hall, 1995.

[18] SILVA, K.R.I. Biodegradação de polietileno tereftalato (PET) por fungos ligninolíticos, Dissertação de Mestrado, UNICAMP, Campinas, 193p. 2009

[19] DOMB, A.J, KOST, J., WISEMAN, D. "Handbook of Biodegradable Polymers”, Amsterdam, Harwood academic publishers. 2010.

[20] VERT, M., LI, S., GARREAU, H., "More abaut degradation of LA/GA-derived matrices in aqueous media”, Journal Controlled Release, v.16, n.1-2, pp.15-25, 1991

[21] FERNÁNDEZ, J., LARRAÑAGA, A., ETXEBERRÍA, A., et al., "Effects of chain microstructures and derived crystallization capability on hydrolytic degradation of poly(l-lactide/ع-caprolactone) copolymers", Polymer Degradation and Stability, v. 98, n. 2, pp. 481-489, 2013.

[22] PEZZIN, A.P.T. Obtenção, Caracterização de blendas de Poli (para-dioxanona) / Poli (L-Ácido láctico) (PPD / PLLA) para aplicação como prótese de menisco bioreabsorvível, Tese de Doutorado, Universidade Estadual de Campinas, Brasil, 2001.

[23] TSUJI, H., SUZUYOSHI, K.,“Environmental degradation of biodegradable polyesters 1. poly ( $\varepsilon-$ caprolactone), poly[(R)-3- hydroxybtyratel, and poly(L-lactide) films in controlled static seawater", Polymer, v.75, pp. 347, 2002.

[24] PARK , C.H., KANG, Y.K., Im, S.S., "Biodegradability of Cellulose Fabrics", Journal of Applied Polymer Science, v. 94, n.1, pp. 248-253, 2004.

[25] GAN, Z., DONGHONG, Y., ZHIYUAN, Z., et al., "Enzymatic degradation of poly( $\varepsilon$-caprolactone)/ poly(DL-lactide) blends in phosphate buffer solution”, Polymer, v.40, n.10, pp.2859-2862, 1999.

[26] PENG, H., LING, J., LIU, J., et al.," Controlled enzymatic degradation of poly (3-caprolactone)-based copolymers in the presence of porcine pancreatic lipase", Polymer Degradation and Stability, v. 95, n. 4, pp. 643-650, 2010. 